\title{
Lacunza en México
}

Bajo el seudónimo de Juan Josafat Ben-Ezra, "hebreocristiano", el jesuita chileno Manuel Lacunza (1731-1801), asilado en Italia desde la expulsión (1767), concluye en 1790 un tratado milenarista que le ha llevado años de trabajo. Su Venida del Mesias en gloria y majestad sostiene, desde luego, que Cristo volverá a la tierra en el sexto milenio de la Creación y que, durante su reinado, todo será paz y felicidad hasta el Día del Juicio. Sólo que el libro se caracteriza por una severa crítica de textos patrísticos y postpatrísticos, y por la "insistencia en retrotraer las interpretaciones cristianas a sus fuentes hebreas y conciliar ambas en su visión mesiánica".1

Aunque, según Domingo Faustino Sarmiento, el interés por el milenarismo no habìa sido extraño al ámbito americano, fue Lacunza quien, fuera de su patria, trató el tema en forma sobresaliente. ${ }^{2} \mathrm{La}$ obra, aun antes de terminada, habia circulado en fragmentos o resúmenes no siempre fieles. Su lectura tuvo inmediata resonancia tanto entre los religiosos como entre los laicos, y las traducciones proliferaron aun antes de que el libro se imprimiera en español. ${ }^{3}$ Admiración entusiasta, repulsa indignada y una desconfianza hasta cierto punto justificada acogieron la Venida lo mismo en Europa que en América.

El texto, como ya habìa ocurrido con otros sobre el mismo asunto ${ }^{4}$, despertó las suspicacias de la Inquisición. En 1789 , la de Lima reprobó la obra, entonces inconclusa, por considerarla "impia, errónea y herética", la de México la suspendió antes de 1821 , y en 1824 el Santo Oficio de Roma la incluyó en el Index; todavía en 1941 el Tribunal consideraba que "el sistema milenarista, aun el mitigado ... no se puede enseñar sin peligro" (Lewin, art. cit.). Pero 
los teólogos no siempre estuvieron de acuerdo en lo que se refiere a la heterodoxia o la peligrosidad de la Venida, como bien lo ilustra un legajo mexicano de principios de 1824, hoy en la Houghton Library (Harvard University). 5

El 24 de febrero de 1824, el provisor y gobernador del Arzobispado de México encarga al "reverendo padre doctor y maestro don Manuel Gómez Marin, presbítero de oratorio de San Felipe Neri", revisar el Discurso en que se manifiestan las falsedades y errores de Juan Josafat Ben-Ezra acerca de la Iglesia Cristiana de Pedro Narciso Blanco, capellán del Convento de Santa Rosa de Puebla, quien habia solicitado la licencia eclesiástica por intermedio del doctor Ignacio Marìa Lerdo, capellán del Colegio de Niñas en la ciudad de México ( $f$. $\left.1 \mathrm{r}^{\mathrm{O}}\right)$.

Habiéndose excusado el padre Gómez Marín por razones de salud el 26 de febrero, dos días después se encarga de la comisión al bachiller José Marìa Sartorio. Su dictamen (f. $2 \mathrm{r}^{\mathrm{O}}-\mathrm{v}^{\mathrm{O}}$ ), fechado en marzo, es favorable al Discurso en cuanto que nada contiene contra los dogmas de la Iglesia; pero formula algunas objeciones. La primera consiste en el temor personal de Sartorio de contribuir con su juicio a la publicación de un escrito que intenta impugnar la Venida. Considera que los méritos dilucidatorios del libro de Lacunza respecto del sistema del milenario han sido reconocidos por la mayoría de los teólogos, que "aplaudió la obra como excelente", si bien el clamor adverso y empecinado de los menos provocó la suspensión temporaria de la lectura "del Josafat" mediante un edicto del Tribunal de la Inquisición de México; con todo, "si la Inquisición subsistiese [habia sido suprimida en 1821], ya hubiera sin duda levantado esa suspensión a vista del aplauso con que lo ha recibido el común de los sabios teólogos". La segunda objeción de José María Sartorio pone en tela de juicio la capacidad y destreza del capellán de Santa Rosa en la realización del Discurso, lo cual inhabilita la obra como refutación efectiva y le resta cualidades para merecer la licencia: "yo aprobaria la salida a luz del Discurso, si el autor impugnase con invencible solidez; mas yo no hallo ésta". Por motivos de salud y de edad, Sartorio se excusa de precisar minuciosamente los defectos del escrito examinado y sugiere se someta a alguien que posea los debidos conocimientos para el caso: "Cualquier teólogo que tenga estas ventajas podrǐa hacerlo muy fácilmente, como, al contrario, a quien pretendiese impugnar la obra sólidamente el copete le sudaria". Antes de terminar, vuelve a insistir: "no tengo ánimo de dar mi voto para que esta grande obra [la Venida] baje del crédito que ha merecido, sea tratada como llena de falsedades, de errores, de herejías, $y$ 
de esta manera se frustren los altos fines que a su sabio autor impelieron a trabajar treinta años en su laboriosa composición". Finalmente, se somete a la decisión superior del provisor: "No obstante, si basta que su impugnación no contenga cosa que se oponga a los santos dogmas, como en efecto no la he hallado, hará vuestra señorìa lo que le parezca mejor. Yo me rindo a su juicio".

El 30 de marzo se pide el parecer del reverendo padre doctor y maestro Manuel Mercadillo, de la orden de Nuestra Señora de la Merced; éste lo presenta el 23 de abril (ff. $2 \mathrm{v}^{\circ}-4 \mathrm{r}^{\circ}$ ). Mercadillo, quien ya habìa expuesto su opinión favorable a la Venida ante "los señores jueces de la extinguida Inquisición", confiesa que la demora en presentar su parecer se ha debido en parte a una dificultad relativa al texto de la obra impugnada. Habiéndola leỉdo antes "en la errada impresión de la Puebla" y "en la versión latina por ... el padre don Juan Ignacio Maneiro", ocupó parte del tiempo "en solicitud de la impresión de don Felipe Tolosa", la empleada por Pedro Narciso Blanco, con el fin de "cerciorarse si ella ha reportado, lo que muchas veces acontece, alguna mutación refundida en lo substancial". Se detuvo "en el dictamen hasta no haber a las manos la impresión de Tolosa por si tuviera algún vicio considerable", pues recordaba la mala fe con que "viciaron en Roma la impresión los rivales del Josafat" y consideraba "que la impresión podría adoptar vicios muy distantes del sentir del autor, y que de este modo hubiera venido a manos del impugnador".

El problema textual que tan concienzuda y honradamente trató de resolver el padre Mercadillo fue el mismo con que tropezó el general argentino Manuel Belgrano cuando se propuso preparar una edición de la Venida; éste dice a propósito del primer ejemplar impreso que cayó en sus manos: "la impresión ... . está tan llena de errores, y errores tan substanciales, que puede decirse sin exageración, habría sido... menos sensible ... carecer por mucho tiempo de la obra que tenerla al punto en una forma que sólo puede servir para denigrarla, haciéndola digna de una justa censura . . . la repetida falta de periodos enteros y trueque de palabras es principalmente lo que la hace insufrible, siguiéndose de esto necesariamente que unas veces se lean despropósitos y no pocas proposiciones erróneas, y aun heréticas, afirmándose de Jesucristo lo que corresponde al Anticristo, o viceversa" (Lewin, art. cit.). Fue también la dificultad de quienes trabajaron en la edición de Londres de 1826.6 Según la "Advertencia" que la encabeza, la obra ha tenido mala suerte, pues sus ediciones han sido defectuosisimas, "de modo que hasta ahora el público no ha podido formarse una idea cabal del magnífico monu- 
mento elevado por Lacunza a las ciencias eclesiásticas" (p. V); esto obligó a los editores a un cuidadoso trabajo de cotejo y selección para escoger "el sentido que ha parecido más análogo a las miras del autor, a más de reemplazar textos suprimidos" (p. VI). Cabe preguntarse si tales errores-fueran accidentales o intencionados-tanto en las copias manuscritas como en las ediciones determinaron los veredictos condenatorios contra Lacunza, o si éstos se debieron puramente al milenarismo que el jesuita sustentaba.

Aparte del problema referente a la impresión de Tolosa-que el padre Mercadillo no parece haber encontrado-, el mercedario se enfrentó con otros dos: su propia admiración por Lacunza y la "repetida lectura de la impugnación", causas que contribuyeron también a demorar el dictamen. Mercadillo confiesa sinceramente que le fue preciso desnudarse "en semejante estado ... de los afectos al Josafat para evitar preocupaciones o juicios anticipados con el fin de calificar la obra, o cuaderno, del impugnador" y atenerse "al paso de las razones, solidez de los argumentos y tino con que maneje la fuerza del convencimiento".

Mercadillo aplica metódicamente este proceder, y encuentra: 10) que el impugnador falta "a las reglas de la buena crítica y a las de probabilidad hermanéutica", pues sólo se muestra decidido a hallar falsedades y errores en la Venida; $2^{\circ}$ ) que "con gran ligereza se precipita a censurar con notas teológicas" y cae así en una actitud que, partiendo de una diferencia de opinión, puede provocar "desafectos de voluntad en extremo perjudic[i] ales", a más de anticiparse a la sentencia de la Iglesia; $3^{\circ}$ ) que no se limita a discutir ("no nos persuadamos a que esto dice via arguendi"), sino que busca errores premeditadamente, "pues jamás en el frontispicio se hallan deducciones, sino que con sólo le[e] rlo se encuentra su decisión, pues su título es: Discurso en que se manifiestan las falsedades y errores de Juan Josafat Ben-Ezra"; 40) que, si bien ortodoxas, las razones del impugnador "tienen cierta debilidad comparadas con las propuestas por el autor Lacunza .... y no convencen", porque les falta fuerza y atractivo para ello. Puntualizadas las objeciones, Mercadillo propone se otorgue la licencia solicitada, "siempre que el impugnador de la obra de la Venida de J[esu] C[risto] en pompa [sic] y majestad quite las notas denigrantes... principalmente las de herejía, error, improba[bi] lidad", etc.

El 28 de abril se concede la licencia si la impugnación se ajusta a los términos sugeridos por Mercadillo y se pide al padre calificador indique qué debe suprimirse en el Discurso (f. $4 \mathrm{r}^{\circ} \mathrm{v}^{\mathrm{O}}$ ). 
Precedidas de una breve introducción y con fecha 17 de mayo de 1824, el padre Mercadillo especifica "las proposiciones denigrantes que se deban tildar a fin de que pueda correr la obra del impugnador" (ff. $4 \mathrm{v}^{\mathrm{O}}-6 \mathrm{v}^{\circ}$ ). Subraya también la necesidad de las correciones para que "puedan los sabios conocer quién de ellos [Blanco o Lacunza] en materia tan delicada habla con más nervio y solidez"; insiste además en que con ellas se evitará "la guerra de opiniones ...., que aunque ocurra diferencia entre opiniones verdaderamente católicas, se conserve la paz entre los autores, o sus apologistas, evitadas las notas teológicas, que en extremo perjudican a la fama y buen concepto, sin prevenir el juicio de Nuestra Madre la Santa Iglesia".

En primer lugar, el padre Mercadillo señala que deben reemplazarse en el título de la portada las palabras falsedades y errores por doctrinas y opiniones. Censura los dos primeros folios y parte del tercero del "Exordio" proponiendo se le suprima por completo o se redacte de nuevo, "por llamar al sentir del autor especies falsas, erróneas, contra la Iglesia de Roma y de Jesucristo" y asegurar "que el Josafat conviene con los herejes de las confesiones augustana ${ }^{7}$ y de Vuitembert ${ }^{8}$, llamados por esta causa protestantes"; según Mercadillo, el impugnador no advierte las diferencias entre el sentir del padre Lacunza y la actitud de los herejes con quienes lo compara, como tampoco que el impugnado sólo deduce fenómenos y "habla en hipótesis". Después de indicar que debe borrarse un pasaje de donde se deduciría, de acuerdo con el padre Blanco, que Lacunza concede infalibilidad a la Iglesia activa, pero se la niega a la pasivaafirmación que Mercadillo considera antojadiza-, el censor dice que debe seguirse el mismo procedimiento con otros dos, pues carecen de base $\circ$ referencia a autoridades. Recomienda luego un cambio de expresión por no encontrar que lo afirmado por Lacunza induzca a los lectores a errar, sino que es simplemente una opinión que difiere de la sustentada por su impugnador. Mercadillo pide también se borre otra línea porque "según los tiempos varian las proposiciones" $y$ "una misma proposición según la diversidad de los tiempos puede ser o no de fe"; por lo demás, debe observarse de qué boca salen las proposiciones, pues, aunque reprobables y heterodoxas empleadas por herejes, son dignas de aplauso y ortodoxas si quien las usa es un católico. El mercedario critica a continuación, e indica que debe quitarse, todo un párrafo donde el padre Blanco acumula en pie de igualdad varias herejías y opiniones: “¿Qué embrollamiento de ideas! ¡Confundir las herejías entre sǐ...! ¿Podrá darse mayor diversidad entre los errores de Lutero y Calvino y de los Jansenis- 
tas?". La impropiedad de una lectura ("No dice que es, sino que será") y la inconsistencia de la afirmación ("el mismo impugnador confiesa que el mismo Josafat es el primero que promueve semejante desatino. Si es el primero el padre Lacunza, luego no conviene con Lutero") son motivo de que Mercadillo indique otras supresiones. También merecen este veredicto el atribuir a Lacunza la doctrina sustentada por Calvino y los modernos herejes de que la infalibilidad reside "en el conjunto de los fieles y no de los pastores", cuando en "repetidas ocasiones asegura el padre Lacunza la infalibilidad de la Iglesia activa o de los pastores", y el afirmar "con temeridad . . . afectada moderación" al tachar a Lacunza de convenir "con los enemigos de la Iglesia". Mercadillo no se limita a censurar lo que va contra el buen crédito del autor de la Venida, sino también contra el de otros: "Pienso igualmente se debe quitar la nota toda 16 por llamar temerarios al grande Bos[s] uet, al insigne Fleuri [sic], y no tiene embarazo en decir lo mismo del Josafat, porque asegura haber éste causado más daños que los autores antecedentemente citados". La agresiva pretensión de Blanco de que, si se reduce su impugnación para favorecer a Lacunza, sólo se probará su conformidad doctrinaria con herejes e impios, determina una nueva eliminación por considerar Mercadillo que es "proposición en verdad avanzada". Finalmente el censor aconseja se agregue una nota aclaratoria a un párrafo donde Blanco afirma que el Arzobispo de Malines, M. de Pradt, atribuye a Pío VII haber convenido, por el concordato celebrado con el rey de Prusia, "de grado en el culto de la estatua de Martín Lutero en Wittemberg". Para Mercadillo, "la proposición según su fondo y sonido es por lo menos malsonante, temeraria, et piarum aurium offensiva, denigrando la fama, el honor y reputación de la sabiduría y santidad del señor Pío VII, sin designar cuál es el culto y en qué términos se concedió"; en realidad, se trata de un caso de tolerancia ad maiora vitanda y de "culto no religioso, sino puramente civil", como el que se tributa a los grandes hombres "por su sabiduria, por su gobierno o por su pericia militar".

La impresión general a que se llega respecto del Discurso del padre Blanco es la de que su autor no era sólo incongruente y poco diestro, sino, además, atrabiliario; pero como el texto no se incluye en el manuscrito, y es posible que nunca se publicara ${ }^{9}$ - ¿acaso porque Blanco no aceptó los cortes y modificaciones impuestos por la censura? -, no tenemos más remedio que quedarnos con la imagen 
sugerida por quienes participaron en la calificación y el informe, todos los cuales eran, sin duda alguna, decididos admiradores de Lacunza.

Harvard University

Wheaton College, Massachusetts

RAIMUNDO LIDA EMMA SPERATTI

\section{NOTAS}

1. Boleslao Lewin, "El general Belgrano y el mesianismo del padre Lacunza", La Prensa, Buenos Aires, 14 de junio de 1970 (Suplemento Dominical, Primera Sección).

2. Cf.: "Sobre el milenarismo han escrito varios haciéndose notar Lacunza, chileno... Mucho antes que él, habĭa ensayado su sagacidad en resolver tan arduo problema, el docto fray Miguel [Albarracĭn]", Recuerdos de provincia, "Los Albarracines", Emecé Editores, Buenos Aires, 1944, p. 83.

3. "Prefacio" de Manuel Belgrano a la edición de Londres (1816), apud Lewin, art. cit.

4. "El infolio que escribió [fray Miguel Albarracin] sobre la materia fue examinado por la Inquisición de Lima, el autor citado ante el Santo Oficio, acusado de herejïa", Sarmiento, op. cit., p. 83.

5. fMS Span 80, "José Manuel [sic] Sartorio et al sobre el Discurso de P. N. Blanco contra Lacunza", 6 folios $\mathrm{r}^{\mathrm{O}} \mathrm{v}^{\mathrm{o}}$. (En las citas que hacemos con autorización de la Houghton Library, modernizamos lả ortografía y la puntuación).

6. La Venida del Mesías en gloria y majestad. Observaciones de Juan Josafat Ben-Ezra, hebreo-cristiano: dirigidas al sacerdote cristófilo. Se dedican al Mesías Jesucristo, Hijo de Dios, Hijo de la Santísima Virgen Marǐa, Hijo de David, Hijo de Abraham. En tres tomos. Tomo I, Londres: Lo publica R. Ackermann, Strand, y en su establecimiento en Mégico: Asimismo en Colombia, Buenos Aires, Chile, Perú, y Guatemala. 1826.

7. ¿Se refiere a las Confesiones de Augsburgo presentadas ante la Dieta por los protestantes en 1530? Redactadas por Melanchton, contenían en veintiocho artǐculos la fe luterana.

8. Es, claro está, la ciudad alemana de Wittemberg donde se encuentra la capilla a cuya puerta fijó Lutero, el 31 de octubre de 1517, sus famosas proposiciones contra las indulgencias, dando comienzo asì a la Reforma protestante.

9. Cf. The Dolphin Books Catalog, núm. 35 (1957), Núm. 39: "The Discurso, however, is not recorded, and presumably it was not printed". 
